\title{
EFFECT OF AMINOGUANIDINE, HISTAMINE, HISTIDINE AND COMPOUND 48/80 ON PREGNANGY IN RATS AND MIGE*
}

UPENDRA K. BANIK, YUTAKA KOBAYASHI AND

MELVIN M. KETGHEL

Worcester Foundation for Experimental Biology, Shrewsbury, Massachusetts, U.S.A.

(Received 23rd April 1963)

It has been suggested by Shelesnyak (1957) that histamine might be the chemical stimulus responsible for the implantation of blastocysts. According to Shelesnyak's hypothesis (1960), an oestrogen surge results in the liberation of histamine, and the released histamine induces stromal cells of the endometrium to transform into decidual cells. Much of the experimental work supporting this hypothesis rests on the observation that, in rats, local application of antihistamine agents to the uterus suppresses the decidual transformation and inhibits the normal implantation of blastocysts.

The possibility remains, however, that the effects of the antihistamines described by Shelesnyak may be non-specific, and interfere with implantation in some manner not involving histamine. The experiments described in the present report were undertaken in an attempt to extend the evidence concerning the possible role of histamine in the process of implantation.

Sprague-Dawley female rats, weighing 200 to $250 \mathrm{~g}$ and white Swiss female mice, weighing 25 to $35 \mathrm{~g}$ were housed with fertile males. Treatment was begun on the day on which spermatozoa were observed in the rats or a vaginal plug was observed in the mice, and the treatment was continued for 6 days.

Aminoguanidine sulphate, dissolved in water, was injected subcutaneously. Histamine dihydrochloride and Compound $48 / 80$ were dissolved in $0.85 \% \mathrm{NaCl}$ and injected intraperitoneally. L-Histidine was dissolved in water and fed by feeding tube. Terramycin was dissolved in tap water $(1.5 \mathrm{~g} / \mathrm{l})$ used as drinking water. Control animals were given injections of the vehicle without the drug, and all injections had a volume of $0.2 \mathrm{ml}$.

The animals were killed on the 13th day of pregnancy. Fourfold contingency test tables (Mainland \& Murray, 1952) were used for statistical analysis of the numbers of pregnant and non-pregnant animals. Statistical analysis of the numbers of foetuses was made according to the single classification of analysis of variance (Snedecor, 1941).

\footnotetext{
-Work aided in part by a grant from the Population Council of New York City and in part by a grant, E-1135, from the National Institute of Allergy and Infectious Diseases, N.I.H., U.S.P.H.S.
} 
The effect of aminoguanidine on pregnancy in mice is shown in Table 1 (Groups 1, 2, and 3). At all concentrations tested there was an increase in the number of non-pregnant mice observed. The inclusion of terramycin in the drinking water of mice receiving aminoguanidine appeared to reduce the effectiveness of aminoguanidine (Groups 4 and 5). In contrast to mice, no effect was observed on pregnant rats after the same relative doses of aminoguanidine, except for a reduction in the average number of foetuses per pregnant rat when the concentration of aminoguanidine reached $200 \mu \mathrm{g} / \mathrm{g}$ rat/day.

TABLE 1

EFFEGT OF AMINOGUANIDINE, HISTAMINE, HISTIDINE AND COMPOUND 48/80 ON PREGNANCY IN MICE

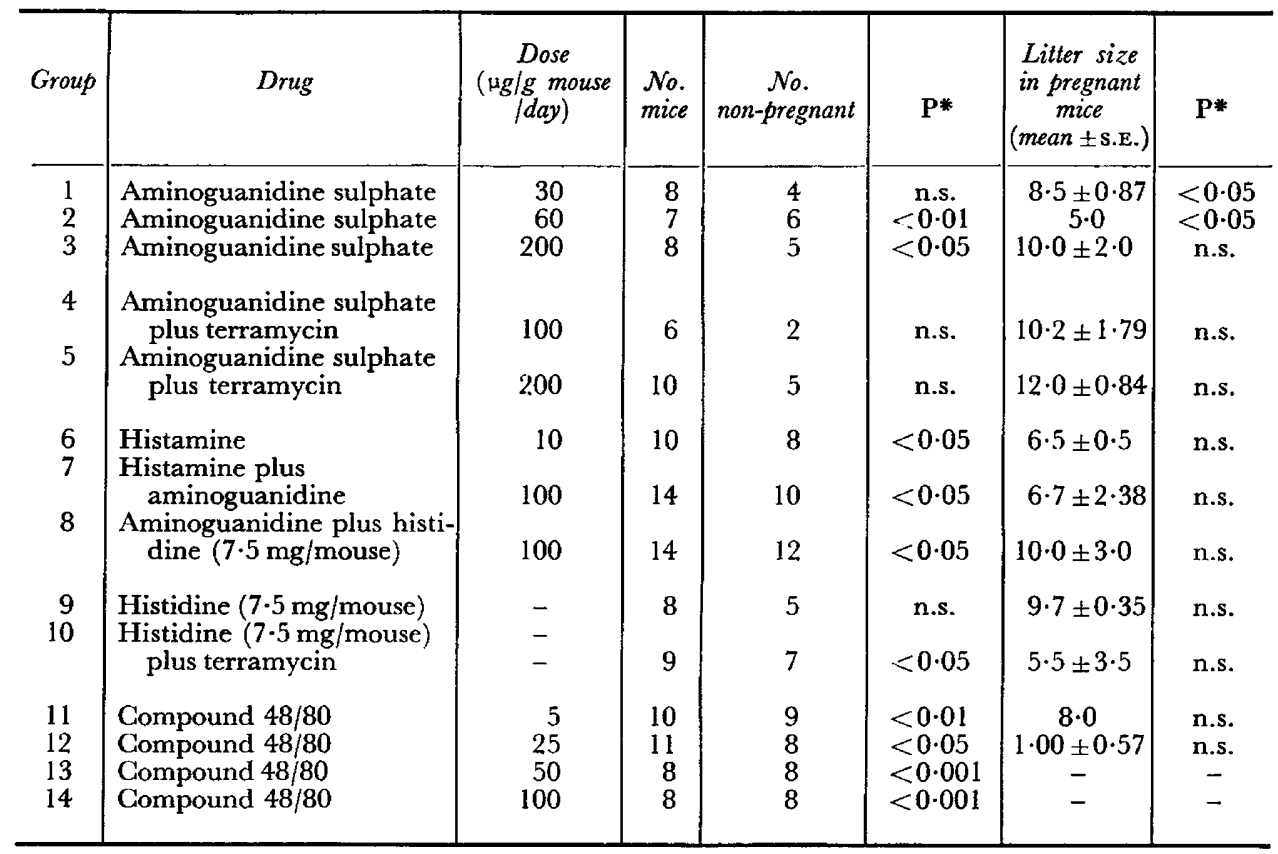

* Compared with the control group. A separate control group, which received the vehicle without the drug, was used for each drug tested.

n.s. $=$ Not significant $(P>0.05)$.

The administration of histamine, histamine plus aminoguanidine, or aminoguanidine plus histidine to pregnant mice caused a significant increase in the number of non-pregnant mice (Groups 6, 7 and 8). The same relative doses of these compounds administered to pregnant rats caused no significant increase in the number of non-pregnant rats, although the average litter size was somewhat reduced by histamine and by the combination of histamine and aminoguanidine. Histidine alone or in combination with terramycin (Groups 9 and 10) was able to cause an increase in the number of non-pregnant mice, although it had no effect on pregnancy in rats.

Compound 48/80 was very effective in increasing the number of non-pregnant mice (Groups 11, 12, 13 and 14) but it did not have this effect on rats. 
The administration of a series of drugs aimed at altering the levels of histamine has resulted in the disturbance of pregnancy in mice, but not in rats. It would be advantageous if the Shelesnyak hypothesis could be tested directly by altering the histamine level of the uterus without otherwise affecting the animals. Since this is not possible we have attempted to alter the histamine concentration of the uterus by altering the concentration of circulating histamine. The work of Schayer, Wu \& Smiley (1954), Schayer (1956) and Schayer \& Karjala (1956) indicates that if rats or mice are treated with aminoguanidine and fed histamine, as in the present experiments, an increase in the titre of circulating histamine results. Shelesnyak (1960) has reported experiments which indicate that the histamine of uterine tissue is derived from mast cells, and that the number of uterine mast cells may be effectively depleted by the systemic injection of Compound 48/80.

Apparently the treatments carried out in the present experiments were effective in altering the histamine levels in the animal, and very likely in the uterus. The administration of aminoguanidine to pregnant rats had no apparent effect on implantation in these experiments, thus confirming the earlier observations of Kahlson, Rosengren \& Westling (1958). Indeed, none of the treatments designed to alter the concentration of histamine were effective in disturbing pregnancy in the rat. If histamine release is required for deciduoma formation the treatment of pregnant rats with Compound 48/80 would be expected to impair implantation because of histamine depletion. Since the effectiveness of Compound $48 / 80$ in depleting uterine histamine has been demonstrated by Shelesnyak (1960), our data do not appear to support the contention that histamine release is required for implantation in the rat. Finn \& Keen (1962) have reported that the injection of histamine directly into the lumen of the uterus of the pseudopregnant rat failed to induce deciduoma formation.

In contrast to the rat, implantation in the mouse was affected by all treatments designed to alter the histamine level in the animal. Thus the administration of aminoguanidine, histamine or histidine, all of which would tend to increase histamine levels, caused a reduction in the number of successful pregnancies in the mouse. The treatment of pregnant mice with Compound 48/80, which decreases the tissue content of histamine (Riley, 1959), also impaired implantation. The effectiveness of the minute amount of Compound 48/80 used was striking. These preliminary data indicate that either an increase or a decrease of histamine in the mouse is detrimental to the establishment of pregnancy.

\section{REFERENCES}

FinN, C. A. \& Keen, P. M. (1962) Failure of histamine to induce deciduomata in the rat. Nature, Lond. 194, 602.

KAHLSON, G., RosengRen, E. \& Westuing, H. (1958) Increased formation of histamine in the pregnant rat. F. Physiol. 143, 91 .

Mainland, D. \& Murray, I. M. (1952) Tables for use in fourfold contingency test. Science, 116, 591.

RILEY, J. F. (1959) The mast cells. Livingstone, Edinburgh.

Schayer, R. W. (1956) The metabolism of histamine in various species. Brit. F. Pharmacol. 11, 472.

Schayer, R. W. \& Karjata, S. A. (1956) Ring N methylation, a major route of histamine metabolism. 7. biol. Chem. 221, 307. 
Schayer, R. W., Wu, K. Y. T. \& Smiley, R. L. (1954) Sources of urinary histamine in the rat. Amer. F. Physiol. 179, 481.

SHELESNYAK, M. C. (1957) Some experimental studies on the mechanism of ova implantation in the rat. Recent Progr. Hormone Res. 13, 269.

Shelesnyak, M. C. (1960) Nidation of the fertilized ovum. Endeavour, 19, 81.

SNEDECOR, G. W. (1941) Statistical methods applied to experiments in agriculture and biology, 4th edn., p. 214. Iowa State College Press. 